\title{
Erratum to: Transparent Rectifying Contacts for Visible-Blind Ultraviolet Photodiodes Based on $\mathrm{ZnO}$
}

\author{
A. LAJN,${ }^{1,2}$ M. SCHMIDT, ${ }^{1}$ H. VON WENCKSTERN,${ }^{1}$ \\ and M. GRUNDMANN ${ }^{1}$ \\ 1.-Fakultät für Physik und Geowissenschaften, Institut für Experimentelle Physik II, Universität \\ Leipzig, Linnéstraße 5, 04103 Leipzig, Germany. 2.—e-mail: lajn@uni-leipzig.de
}

\section{Erratum to: Journal of ELECTRONIC MATERIALS DOI 10.1007/s11664-010-1395-x}

Under the Results section in the original article, the second paragraph was inadvertently omitted. The omitted text is as follows:

While the transmission of the platinum-based contact is only weakly dependent on the wavelength of the incident light, the transmission of the silver-based contact decreases remarkably for wavelengths below $550 \mathrm{~nm}$. The latter effect is caused by absorption in the silver oxide, as the respective fundamental absorption edge was determined by spectroscopic ellipsometry on thicker $\operatorname{Ag}_{x} \mathrm{O}$ films to be at about $2.3 \pm 0.2 \mathrm{eV}$ (not shown here). The $\mathrm{PtO}_{y}$ and the $\mathrm{Ag}_{x} \mathrm{O}$ contacts achieve a mean transmission in the visible spectral range of $75 \%$ and $73 \%$, respectively. At the $\mathrm{ZnO}$-free exciton energy at room temperature $\left[\left(3.31 \mathrm{eV}^{14}\right)\right.$, indicated by dotted lines in Figs. 1 and 3], the $\mathrm{PtO}_{y}$ and the $\mathrm{Ag}_{x} \mathrm{O}$ contacts still transmit $69 \%$ and $51 \%$ of the incident light, respectively. 